\title{
Association Between Joint Hypermobility and Gastroesophageal Reflux Disease: An Observational Analytical Cross Sectional Study
}

\author{
Ziad AL-R AWI, ${ }^{1}$ Faiq GORIAL, ${ }^{1}$ Ayman ALI SALMAN ${ }^{2}$ \\ ${ }^{1}$ College of Medicine, Medicine-Rheumatology, Baghdad, Iraq \\ ${ }^{2}$ Baghdad Teaching Hospital, Medicine-Rheumatology, Baghdad, Iraq
}

\begin{abstract}
Objectives: This study aims to assess the association between joint hypermobility (JHM) and gastroesophageal reflux disease (GERD).

Patients and methods: This cross sectional study included 100 consecutive Iraqi patients (43 males, 57 females; mean age $30 \pm 6.6$ years; range 18 to 40 years) with GERD diagnosed by a gastroenterologist according to the guidelines for diagnosis and management of GERD and age and sex matched 100 healthy controls ( 36 males, 64 females; mean age $30 \pm 5.2$ years; range 20 to 40 years). JHM was measured using Beighton score method by a blinded observer. A score of 4 or more was considered hypermobile.

Results: Joint hypermobility values were significantly higher in GERD patients than in controls [46 (71.9\%) vs 18 (28.1\%), $\mathrm{p}<0.001$, odds ratio=3.88; $95 \%$ confidence interval=2.04-7.39]. Multiple logistic regression analysis to detect predictors of GERD in JHM patients revealed that patients with high total mobility score (7-9) had the highest risk for developing GERD [about 41 fold compared to those with normal mobility score (<4), P model $<0.001$, and overall prediction accuracy of $68 \%]$.

Conclusion: There is a significant association between JHM and GERD. The high total mobility score (7-9) was associated with a significantly high risk for developing GERD, indicating that early recognition of JHM may assist in early diagnosis and treatment of GERD.

Keywords: Beighton score; gastroesophageal reflux disease; joint hypermobility.
\end{abstract}

A hyper mobile joint is a joint with motion range which is above normal values regarding age, sex, and race. ${ }^{1}$ Benign joint hypermobility syndrome (BJHS) is the occurrence of musculoskeletal symptoms in the hyper mobile individuals in absence of systemic rheumatologic disease. ${ }^{2}$ Gastroesophageal reflux disease (GERD) is a disease characterized by a retrograde movement of gastric contents into the esophagus leading to symptoms of heart burn, regurgitation, and in severe cases, erosion and inflammation of esophageal mucosal lining. ${ }^{3}$ A systematic review has shown the prevalence of GERD to be
10 to $20 \%$ in the western world with a lower prevalence in Asia. ${ }^{4}$

It is intriguing that most of the extra-intestinal features of functional gastrointestinal disorder are the same with features of BJHS which is a non-inflammatory connective tissue disorder. Furthermore, patients with BJHS may also display unexplained gastrointestinal symptoms. ${ }^{5}$ Despite this overlap, the possibility that a proportion of patients with connective tissue abnormality, such as BJHS, has been explored by one study that assessed joint mobility in patients with unexplained gastrointestinal symptoms. ${ }^{6}$ Therefore, in this 
study, we aimed to assess the association between joint hypermobility (JHM) and GERD.

\section{PATIENTS AND METHODS}

This cross sectional study was conducted at Gastroenterology Unit, Medical Department, Baghdad Teaching Hospital between June 2013 and June 2014. The study included 100 consecutive Iraqi patients (43 males, 57 females; mean age $30 \pm 6.6$ years; range 18 to 40 years) of GERD who presented with heartburn and regurgitation and were diagnosed by a gastroenterologist according to the guidelines for diagnosis and management of GERD $^{7}$ and age and sex matched 100 healthy controls (36 males, 64 females; mean age $30 \pm 5.2$ years; range 20 to 40 years). Joint mobility was measured in both groups. The study protocol was approved by the Ethics Committee of Baghdad University of Medical Sciences, and a written informed consent was obtained from each participant in the study.

Patients with other comorbid diseases or other causes of upper gastrointestinal symptoms were excluded. Patients' name, age, and sex were recorded as well as body height and weight with indoor clothing and without shoes. Then, body mass index (BMI) was calculated according the equation $\mathrm{BMI}=$ weight/height. ${ }^{2}$ Joint mobility in both groups was evaluated blindly by another observer using Beighton method. ${ }^{8}$ Participants scoring 4 or more were considered hypermobile.

\section{Statistical analysis}

Statistical software PASW version 18.0 (SPSS Inc., Chicago, IL, USA) was used for analysis. Kolmogorov-Smirnov test was used to assess the normal distribution of continuous data. The normally distributed continuous variables were presented as mean \pm standard deviation and categorical variables as number and percentages. $\mathrm{T}$ test for independence was used to test the significance of association for continuous variables and Chi-square test for categorical variables. Multiple logistic regression analysis was used to assess predictors of GERD in JHM. A $p$ value of $<0.05$ was considered statistically significant.

\section{RESULTS}

The mean BMI was $24 \pm 2.9 \mathrm{~kg} / \mathrm{m}^{2}$ for GERD patients and $24 \pm 3.4 \mathrm{~kg} / \mathrm{m}^{2}$ for controls. The mean of age, sex, and BMI showed no statistical significant difference between the groups ( $p>0.05$ ). Sociodemographic variables were similar between both groups.

Joint mobility was normal in 54 (39.7\%) GERD patients and in 82 controls (60.3\%). JHM was present in 46 (71.9\%) GERD patients and $18(28.1 \%)$ controls $(p<0.001$, odds ratio $=3.88$; $95 \%$ confidence interval=2.04-7.39) indicating a statistical significant difference between both groups as shown in Figure 1.

Multiple logistic regression analysis to detect predictors of GERD in JHM patients revealed that patients with high total mobility score (7-9) had the highest risk for developing GERD [about 41 fold compared to those with normal mobility score $(<4), p$ model $<0.001$, and overall prediction accuracy of $68 \%$ as shown in Table 1].

\section{DISCUSSION}

This study aimed to assess JHM in patients with GERD and interestingly showed that JHM was approximately four folds more common in GERD patients than controls. This finding is statistically and clinically significant since it may indicate that patients with JHM are more prone to GERD. The high total mobility score was associated with a significantly high risk for developing GERD.

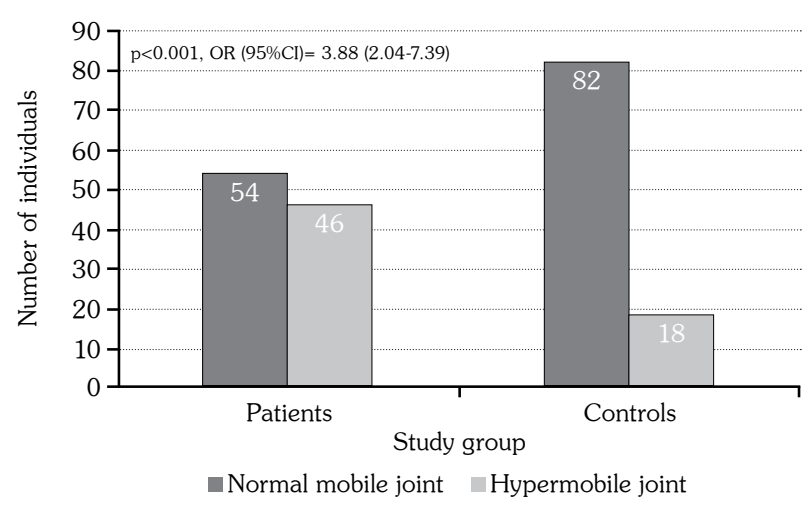

Figure 1. Comparison of joint mobility in GERD patients and controls. $\mathrm{P}$ value is significant; OR: Odds ratio; $\mathrm{CI}$ : Confidence interval. 


\begin{tabular}{|c|c|c|c|c|c|}
\hline \multirow[b]{2}{*}{ Variables } & \multirow[b]{2}{*}{$\%$} & \multirow[b]{2}{*}{$p$} & \multirow[b]{2}{*}{ OR } & \multicolumn{2}{|c|}{ 95\% CI for (OR) } \\
\hline & & & & Lower & Upper \\
\hline Age (years) & & 0.002 & 1.106 & 1.039 & 1.178 \\
\hline Female sex compared to male & & 0.360 & 0.747 & 0.400 & 1.395 \\
\hline Body mass index & & 0.609 & 1.026 & 0.929 & 1.133 \\
\hline Joint mobility score categories & & 0.000 & & & \\
\hline Joint mobility score 4-6 compared to negative $<4$ & & 0.001 & 4.301 & 1.850 & 9.996 \\
\hline Joint mobility score $7-9$ compared to negative $<4$ & & 0.000 & 41.476 & 8.028 & 214.275 \\
\hline Constant & & 0.001 & 0.029 & & \\
\hline P model & & $<0.001$ & & & \\
\hline Overall prediction accuracy & 68 & & & & \\
\hline
\end{tabular}

The pathophysiology of GERD in JHM is not fully explained. Possible mechanisms are as follows. (i) The complex connective tissue matrix may contribute significantly to the passive mechanical properties of the extracellular matrix of the gastrointestinal tract and relevant changes in the connective tissue of the muscularis externa that subsequently influence their function. ${ }^{9}$ (ii) Impaired autonomic nervous system function could be another potential pathophysiological link between GERD and JHM. ${ }^{10}$ It has been hypothesized that the autonomic nervous system dysfunction may be responsible for the anomalous viscerovisceral and viscero-somatic motor reflexes resulting in gut dysmotility. ${ }^{11}$ (iii) Ligamentous laxity and weakness of supporting structures may be etiological factors due to abnormality in collagen in JHM patients. ${ }^{12}$

In this study, the observed significant increase in frequency of JHM in patients with GERD compared to healthy controls was in agreement with another study conducted by Zarate et al. ${ }^{6}$ who found increased reflux symptoms in JHM patients.

Another noteworthy observation in this study was that high total mobility score (7-9) was associated with about 41 fold increased risk for developing GERD in JHM patients than in controls which was in line with other studies that reported increased total mobility score in patients with hiatus hernia ${ }^{13}$ and patients with hemorrhoid ${ }^{14}$ compared to controls.

The main limitations of this study are the small sample size and short study duration. Therefore, further prospective studies with larger sample size and longer duration are required. Furthermore, since we reported a selected group of patients referred to tertiary care, our findings cannot be generalized to patients in primary care. JHM was evaluated in the gastroenterology unit and thus selection bias might be present. Nevertheless; it is accepted that the investigators may have introduced selection bias in those patients with more severe symptoms. ${ }^{15}$

In spite of these limitations, to the best of our knowledge, this is the first case control study investigating JHM in Iraqi patients with GERD. Also, our study revealed a significant clinical application of the association between JHM and GERD that ignited a considerable scientific interest which may help us in follow-up and management of other visceral disorders of hypermobility syndrome.

In conclusion, we demonstrated an increased frequency of JHM in Iraqi patients with GERD compared to healthy controls. High total mobility score was associated with a significantly high risk for developing GERD. Thus, early diagnosis of JHM is recommended for early recognition and management of GERD complications.

\section{Declaration of conflicting interests}

The authors declared no conflicts of interest with respect to the authorship and/or publication of this article.

\section{Funding}

The authors received no financial support for the research and/or authorship of this article. 


\section{REFERENCES}

1. Seçkin U, Tur BS, Yilmaz O, Yağci I, Bodur H, Arasil $\mathrm{T}$. The prevalence of joint hypermobility among high school students. Rheumatol Int 2005;25:260-3.

2. Hakim A, Grahame R. Joint hypermobility. Best Pract Res Clin Rheumatol 2003;17:989-1004.

3. Fraser A, Delaney B, Moayyedi P. Symptombased outcome measures for dyspepsia and GERD trials: a systematic review. Am J Gastroenterol 2005; 100:442-52.

4. Dent J, El-Serag HB, Wallander MA, Johansson S. Epidemiology of gastro-oesophageal reflux disease: a systematic review. Gut 2005;54:710-7.

5. Hakim AJ, Grahame R. Non-musculoskeletal symptoms in joint hypermobility syndrome. Indirect evidence for autonomic dysfunction? Rheumatology (Oxford) 2004;43:1194-5.

6. Zarate N, Farmer AD, Grahame R, Mohammed $\mathrm{SD}$, Knowles $\mathrm{CH}$, Scott SM, et al. Unexplained gastrointestinal symptoms and joint hypermobility: is connective tissue the missing link? Neurogastroenterol Motil 2010;22:252-78.

7. Katz PO, Gerson LB, Vela MF. Guidelines for the diagnosis and management of gastroesophageal reflux disease. Am J Gastroenterol 2013;108:308-28.

8. Beighton P. Hypermobility scoring. Br J Rheumatol 1988;27:163.

9. Grundy D, Schemann M. Enteric nervous system. Curr Opin Gastroenterol 2006;22:102-10.

10. Gazit Y, Nahir AM, Grahame R, Jacob G. Dysautonomia in the joint hypermobility syndrome. Am J Med 2003;115:33-40.

11. Kellow JE, Azpiroz F, Delvaux M, Gebhart GF, Mertz HR, Quigley EM, et al. Applied principles of neurogastroenterology: physiology/motility sensation. Gastroenterology 2006;130:1412-20.

12. El-Hassani NB. Hiatus Hernia in Infants. Arab J Med 1985;424-6.

13. Al-Rawi ZS, Al-Dubaikel KY, Al-Sikafi H. Joint mobility in people with hiatus hernia. Rheumatology (Oxford) 2004;43:574-6.

14. Yousif UN, Bird HA. Haemorrhoids and joint hypermobility: a new extra-articular association. Clin Rheumatol 2013;32:523-5.

15. Reilly DJ, Chase JW, Hutson JM, Clarke MC, Gibb $\mathrm{S}$, Stillman $\mathrm{B}$, et al. Connective tissue disorder--a new subgroup of boys with slow transit constipation? J Pediatr Surg 2008;43:1111-4. 